\title{
Using smartphones and tablets in higher education contexts: an exploratory study within a teacher education programme
}

\author{
Davide Parmigiani ${ }^{\text {a }}$, Marta Giusto ${ }^{\text {a }}$ \\ ${ }^{a}$ University of Genoa, Italy, davide.parmigiani@unige.it,0000-0003-0985-3862 \\ ${ }^{a}$ University of Genoa, Italy, marta.giusto@gmail.com
}

\begin{abstract}
This study aimed to analyse and explore the potential opportunities offered by mobile devices to improve the higher education scenario. In particular, the study was conducted within a teacher education programme. The students attended a course called Educational Technology, which focussed on the use of mobile devices (smartphones and tablets) inside and outside the classroom. We examined the impact of mobile learning on students' university activities and the changes in the organisation of their studying activity, their learning strategies and their interaction/cooperation levels. After the course, we administered a questionnaire that highlighted some findings concerning the differences between smartphones and tablets in supporting these aspects. We found that both types of devices improved the interaction/collaboration among students and the search for information, which was useful for studying. However, the organisation of studying and the learning strategies were supported only by tablets and for specific aspects of learning. This exploratory research suggests, on the one hand, some possible solutions to improve the quality of university activities, and on the other, it underlines some difficulties that will be analysed more thoroughly in further studies.
\end{abstract}

Keywords: higher education, mobile school

\section{Introduction}

This exploratory study was conducted at the Department of Education of the University of Genoa at the end of a course called Educational Technology, which is included in the teacher education programme for primary school teachers. We aimed to investigate whether and in what way mobile devices can modify the educational activities of a university subject. We had three main purposes. The first aim was to examine which aspects of a higher education course are most affected by the use of mobile devices. The second aim was to underline the educational opportunities facilitated by the affordances of mobile devices, which can improve the outcome of a higher education course. The third, and more specific, aim was to draw some potential guidelines to improve the qualification level of student teachers with regard to issues arising from the use of mobile devices, to allow them to face the educational and cultural challenges of a digital classroom.

\section{Theoretical framework}

In recent years, we can observe an increasing trend towards integrating mobile learning in higher education contexts and, in particular, within teacher education programmes (Baran 2014). The United Nations Educational, Scientific and Cultural Organization (2012) emphasises mobile devices as a global theme that can expand educational access and support instruction, administration and professional development.

Previous studies have focussed on the educational opportunities offered by small mobile devices, such as the iPod (Mahruf et al. 2010; Coens et al. 2011), mobile phones, smartphones (Seppälä and Alamäki 2003; Aubusson et al. 2009; Ekanayake and Wishart 2014), and tablets (Kearney and Maher 2013; Bates and Martin 2013; Hargis et al. 2013; Hashim 2014), as well as combined situations in which various types of devices have been used (Järvelä et al. 2007; Husbye and Elsener 2013; Herro et al. 2013; Şad and Göktaş 2014). The participants involved in these studies are inservice or pre-service teachers, teacher educators, administrative staff, teacher advisors or developers. 


\section{Using smartphones and tablets in higher education contexts: an exploratory study within a teacher education programme Parmigiani, Giusto}

Research studies on the relationship between mobile devices and teacher education are heterogeneous. This paper can be included in the area of pre-service education because it involves student teachers who had the opportunity to use smartphones and tablets. This choice was made because we wanted to analyse the effect of the devices that are generally used by young teachers for the development of meaningful interaction and learning.

Previous studies that focussed on these issues highlight the importance of the possibility of sharing knowledge and skills through a high level of participation and interaction (Ekanayake and Wishart 2014). Kearney and Maher (2013) emphasise the role of mobile learning approaches for the improvement of higher education and, in particular, for preservice teacher education. They state that "pre-service teachers use the tablets to enhance organisational aspects of their professional learning. They initially use productivity apps in class, often in a "just in time," spontaneous fashion to take notes; plan, evaluate and observe lessons on professional experience; and record and annotate media, including their own multimodal reflections. Many pre-service teachers mention the ability of the mobile device to conveniently keep records of their own learning journey both on and off campus' (Kearney and Maher 2013, p. 81). Broda, Schmidt and Wereley (2011, p. 3150) emphasise the need for educators to adopt a 'progressive ethic for teaching and learning, supporting efforts to think differently and use the technology tools to explore and embody the fluid nature of learning and teaching.'

Schuck et al. (2013) report some advantages of mobile learning, including flexibility, convenience, user-friendliness, an enhanced ability to undertake complex tasks, enhanced communication, opportunities for group learning, and increased sharing and interactions with local and global communities. In this way, the authors perceive mobile devices as vectors that facilitate educational opportunities for the contextualisation and personalisation of learning tasks and as supports for project-based and inquiry-based learning approaches.

The learning activities performed on mobile devices feature a different idea of time-space. Formal learning is traditionally 'characterized by two constants or boundaries: time and space. Learning places occupy fixed, physical spaces which are defined by relatively impermeable boundary objects such as walls, classrooms and school buildings. Mobile devices create what we term malleable spatial-temporal contexts for learning' (Kearney et al. 2012). It is crucial that we recognise and acknowledge the importance of the organisation of the learning environment in terms of timespace because it profoundly affects mobile learning experiences (Ling and Donner 2009).

Kearney et al. (2012) propose a framework to qualify mobile learning experiences through the use of time-space to develop learning and professionalism among students.

Fig. 1 Three distinctive characteristics of m-learning experiences with sub-scales (Kearney et al. 2012).

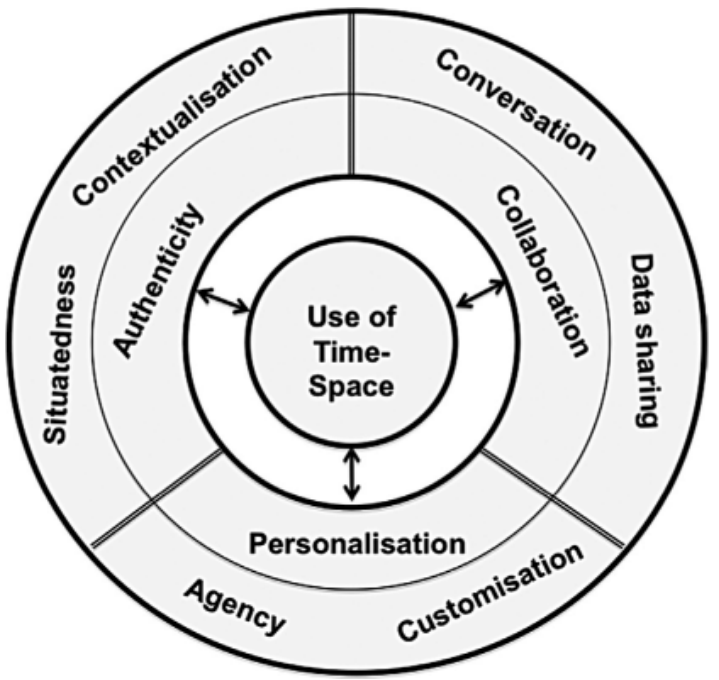

The three distinctive characteristics of mobile learning experiences, with their respective sub-scales, are described by the authors as follows. Authenticity represents the possibility of facing real instructional situations in real contexts. In fact, 'mobile learning episodes potentially involve high degrees of task and process authenticity as learners participate in rich, contextual tasks (setting, characters and tools), involving real-life practices' (Kearney et al. 2012). Learners can generate their own rich contexts (Pachler et al. 2009) with or through their mobile devices. Thus, students have the opportunity to contextualize their learning in situated experiences by participating in a real community of practice. Collaboration among students can be improved through mobile learning experiences because mobile devices support dynamic and just-in-time dialogue and conversation with a high possibility of sharing of material and data that can be retrieved online or generated by students. Finally, personalisation refers to the opportunity offered by mobile devices to customize the learning paths of students. Students can use tools and apps to record, organise and reflect on their own 


\section{Using smartphones and tablets in higher education contexts: an exploratory study within a teacher education programme Parmigiani, Giusto}

learning experiences over time; they can negotiate learning choices (e.g., content and goals); and, ultimately, they can design their own learning paths by selecting, producing or sharing materials.

In our framework, authenticity represents the challenge of modifying university activities (lectures and classes, workshops and teaching practice); collaboration refers to the changes and opportunities in implementing interaction/cooperation among students; and personalisation is connected with potential changes in the studying style and the learning styles and strategies of students.

Our study aimed to analyse how these factors are supported during university activities, such as during a class or in teaching practice. In particular, our framework focusses on the role of the new spatial-temporal dimensions offered by mobile devices to examine how they can modify, enhance, improve and affect students' interaction/collaboration and learning strategies.

\section{Research design}

\subsection{Context and research question}

This research was conducted at the University of Genoa, where a teacher education programme for primary education is offered. This type of programme is a 5-year course. In the fourth year, it offers a subject called 'Educational Technology,' which was attended by student teachers during the first semester of the 2014-15 academic year. This subject focussed on the use of mobile devices at school and was managed by the professor using tablets and smartphones. The professor presented online digital materials, and the students had to elaborate, share and cooperate online through their own mobile devices. For instance, the professor uploaded documents to cloud storage, and the students had to begin an argumentative discussion that highlighted and underlined the most important points while adding comments and exchanging materials.

All students had smartphones, but some of them did not have tablets. In this case, they worked together with colleagues to experience both devices. At the end of the course, the students took two types of examinations. The first was a traditional examination in the form of a written test that focussed on the theoretical aspects included in a textbook. The second was innovative: the students had to simulate a lesson using mobile devices and prepare all the materials.

On the basis of this educational context, we had the opportunity to analyse the main factors of a higher education course that could be affected by mobile devices. The research question can be summarized as follows: has the use of mobile devices affected the main aspects of a university subject? In particular, we wanted to analyse the following areas:

(A) University activities (lectures, workshops and teaching practice);

(B) Changes in individuals' studying style at home;

(C) Changes in students' learning styles and strategies;

(D) Changes in the interaction/cooperation pattern among students.

\subsection{Participants, procedure and instrument}

The participants involved in the study were 49 primary school student teachers. Most of them were women (46, 93.88\%), with an average age $\mathrm{M}=25.102$ years and a standard deviation of 5.11 years. There were three men (6.12\%), with an average age $M=25.33$ years and a standard deviation of 4.04 years.

We chose a mixed approach to collect both quantitative and qualitative data because we wanted to stress on the distinctive benchmarks for the mobile learning activities at the university level and to profoundly understand the reasons for these points of reference.

After the end of the course, we administered an online questionnaire to the participants. The questionnaire was developed by the authors and was composed of 16 closed-ended questions and 4 open-ended questions focussed on the areas indicated in the previous paragraph. Each closed-ended question was divided into two parts. The first referred to smartphones and the second to tablets to identify the differences between the usage patterns of the two types of devices.

In Table 1, we show the structure of the questionnaire. A five-point Likert scale was used to register the responses for the closed-ended questions: Yes, completely = 5; Yes, a lot = 4; Neither yes nor no = 3; No, a little = 2; and Not at all $=1$. The aim of the structure of this questionnaire was to clearly highlight the modalities of students while they were using both smartphones and tablets. 


\section{Using smartphones and tablets in higher education contexts: an exploratory study within a teacher education programme Parmigiani, Giusto}

Table 1. Structure of the questionnaire.

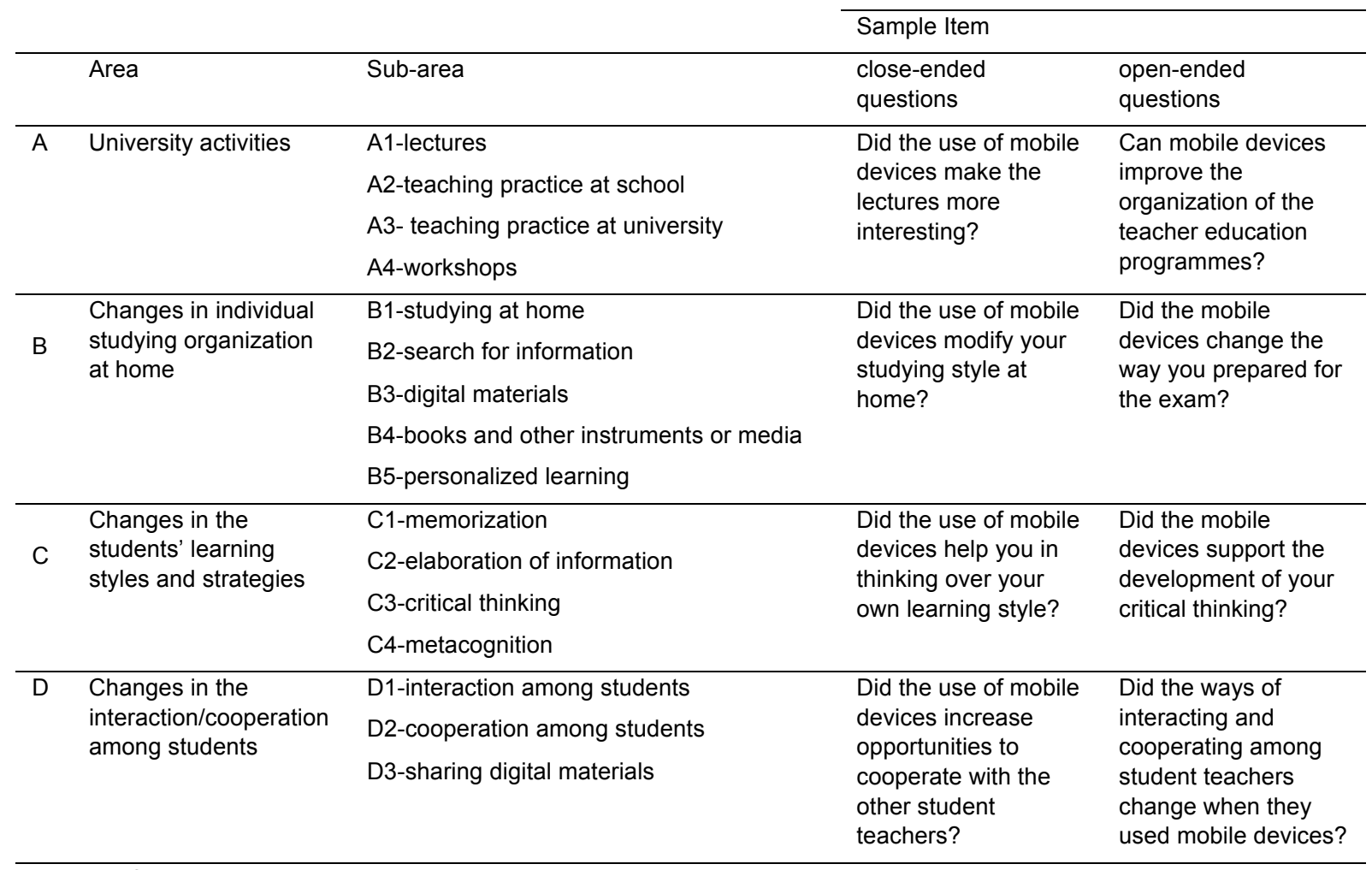

Layout of the closed-ended questions

e.g., C3. Did the use of mobile devices help you in thinking about your own learning style?

\begin{tabular}{|l|l|l|l|l|l|}
\hline$[\mathrm{T}]$ Tablet & Yes, completely & Yes, a lot & Neither yes nor no & No, a little & Not at all \\
\hline [S] Smartphone & Yes, completely & Yes, a lot & Neither yes nor no & No, a little & Not at all \\
\hline
\end{tabular}

\subsection{Limitations}

We must also indicate some limitations of this study. The major issue with this research is that, although the data size is fairly large, it is limited to one university and to the teacher education sector; in addition, it could have been gender biased. We are aware of such limitations and, for these reasons, we cannot generalise the results and draw any conclusions about the organisation of university courses and teacher education programmes. The findings of this research suggest some possible educational solutions that will be analysed in further studies.

\section{Data analysis}

The data analysis focussed on the quantitative data, whereas the qualitative data were used to explain and understand the quantitative results in the discussion paragraph. Table 2 shows the means with standard deviations of all items and the reliability analysis of the questionnaire's areas subdivided into the parts related to smartphones and tablets. For instance, $\mathrm{A}[\mathrm{T}]$ indicates the items included into area A related to tablets, $\mathrm{D}[\mathrm{S}]$ indicates the items included into area $\mathrm{D}$ related to smartphones.

We divided the table into four sectors to highlight the significant aspects. The first sector includes the items that received a high evaluation (greater than 4). These items indicate the aspects of a higher education course that can be easily improved by the affordances of mobile devices. This sector includes items in area D (changes in the interaction/cooperation pattern among students). In particular, the students highlighted the opportunity offered by both types of mobile devices to improve interaction among students (D1) in the exchange of information, the possibility of sharing studying materials (D3) and the retrieval of useful information to study more thoroughly, but only for tablets (B2 [T]). The items in the second sector received a good evaluation (between 3.50 and 3.99). In this part, the students grouped all items of area A (university activities), but only for tablets. In addition, we can find here items related to cooperation among students (D2 [S] and D2 [T]), items related to searching for information with smartphones (B2 [S]), and items related to the elaboration of digital materials with tablets (B3 [T]) and the interaction among different 


\section{Using smartphones and tablets in higher education contexts: an exploratory study within a teacher education programme Parmigiani, Giusto}

instruments and types of media (B4 [T]), still for tablets only. The items in the third sector were evaluated positively but with low scores (between 3.0 and 3.49). In this part, we can find all items of area A (university activities), but only for smartphones, and almost all items of area C for tablets and two items for smartphones (changes in the students' learning styles and strategies). In addition, the items related to changes in studying style at home (B1 [T]) and the personalisation of students' learning paths (B5 [T]) are included. The last items (sector 4) received a negative evaluation (less than 3). Here, we can find most of the items of area B for smartphones (changes in individual studying style at home) and the remaining items of area $\mathrm{C}$ connected to the memorisation and elaboration of information with smartphones.

Table 2. Descriptive statistics.

\begin{tabular}{|c|c|c|c|c|c|}
\hline \multirow{2}{*}{$\begin{array}{l}\text { Item } \\
\text { D3 [T] }\end{array}$} & \multirow{2}{*}{$\begin{array}{l}M \\
4.44\end{array}$} & \multirow{2}{*}{$\begin{array}{l}\text { SD } \\
.801\end{array}$} & & \multicolumn{2}{|c|}{$\begin{array}{l}\text { Cronbach's } \\
\text { Alpha }\end{array}$} \\
\hline & & & & $\mathrm{A}[\mathrm{T}]$ & .777 \\
\hline B2 [T] & 4.24 & .867 & & $A[S]$ & .788 \\
\hline D1 [T] & 4.23 & .863 & Sector 1 & $\mathrm{~B}[\mathrm{~T}]$ & .874 \\
\hline D1 [S] & 4.23 & .992 & & $\mathrm{~B}[\mathrm{~S}]$ & .921 \\
\hline \multirow[t]{2}{*}{ D3 [S] } & 4.12 & 1.071 & & $\mathrm{C}[\mathrm{T}]$ & .805 \\
\hline & & & & $\mathrm{C}[\mathrm{S}]$ & .904 \\
\hline A3 [T] & 3.95 & .783 & & $\mathrm{D}[\mathrm{T}]$ & .797 \\
\hline D2 [S] & 3.93 & 1.107 & & $\mathrm{D}[\mathrm{S}]$ & .825 \\
\hline $\mathrm{A} 4[\mathrm{~T}]$ & 3.90 & .850 & & & \\
\hline B2 [S] & 3.87 & 1.196 & & & \\
\hline $\mathrm{D} 2$ [T] & 3.85 & 1.099 & Sector 2 & & \\
\hline $\mathrm{A} 1[\mathrm{~T}]$ & 3.76 & .913 & & & \\
\hline $\mathrm{A} 2[\mathrm{~T}]$ & 3.68 & .842 & & & \\
\hline B3 [T] & 3.67 & 1.216 & & & \\
\hline $\mathrm{B} 4[\mathrm{~T}]$ & 3.52 & 1.093 & & & \\
\hline $\mathrm{C} 4[\mathrm{~T}]$ & 3.47 & 1.106 & & & \\
\hline $\mathrm{C} 2[\mathrm{~T}]$ & 3.43 & 1.069 & & & \\
\hline C3 [T] & 3.38 & 1.015 & & & \\
\hline A3 [S] & 3.37 & 1.101 & & & \\
\hline B1 [T] & 3.35 & 1.050 & & & \\
\hline B5 [T] & 3.30 & .984 & Sector 3 & & \\
\hline $\mathrm{A} 4$ [S] & 3.24 & 1.116 & & & \\
\hline $\mathrm{A} 1[\mathrm{~S}]$ & 3.16 & 1.079 & & & \\
\hline $\mathrm{A} 2$ [S] & 3.06 & 1.194 & & & \\
\hline C3 [S] & 3.00 & 1.233 & & & \\
\hline C4 [S] & 3.00 & 1.225 & & & \\
\hline B4 [S] & 2.97 & 1.401 & & & \\
\hline C2 [S] & 2.93 & 1.328 & & & \\
\hline $\mathrm{B} 1$ [S] & 2.84 & 1.241 & & & \\
\hline B5 [S] & 2.66 & 1.233 & Sector 4 & & \\
\hline $\mathrm{C} 1[\mathrm{~T}]$ & 2.64 & 1.162 & & & \\
\hline B3 [S] & 2.40 & 1.404 & & & \\
\hline C1 [S] & 2.27 & 1.116 & & & \\
\hline
\end{tabular}

To identify the presence of statistically significant differences between the areas of the questionnaire, we conducted an analysis of variance with repeated measures (rANOVA). Cronbach's Alpha was high for all areas of the questionnaire, so we could aggregate and subdivide the data into the parts related to smartphones and tablets. As shown in Figure 2 and Table 3, we compared the data and found the following: 


\section{Using smartphones and tablets in higher education contexts: an exploratory study within a teacher education programme \\ Parmigiani, Giusto}

- there is a significant difference between the areas related to tablets and the areas related to smartphones (A[T] $\mathrm{A}[\mathrm{S}] ; \mathrm{B}[\mathrm{T}]-\mathrm{B}[\mathrm{S}] ; \mathrm{C}[\mathrm{T}]-\mathrm{C}[\mathrm{S}] ; \mathrm{D}[\mathrm{T}]-\mathrm{D}[\mathrm{S}])$;

- the mean of the area $\mathrm{D}[\mathrm{T}]$ (changes in interaction/cooperation pattern among students with tablets) is statistically significantly always higher compared to all other means;

- the mean of the area C[T] (changes in the learning styles and strategies of students with tablets) is statistically significantly lower compared to other mean values related to the use of tablets;

- the mean of the area $\mathrm{C}[\mathrm{S}]$ (changes in the learning styles and strategies of students with smartphones) is always statistically significantly lower compared to all other mean values.

Fig. 2 ANOVA with repeated measures.

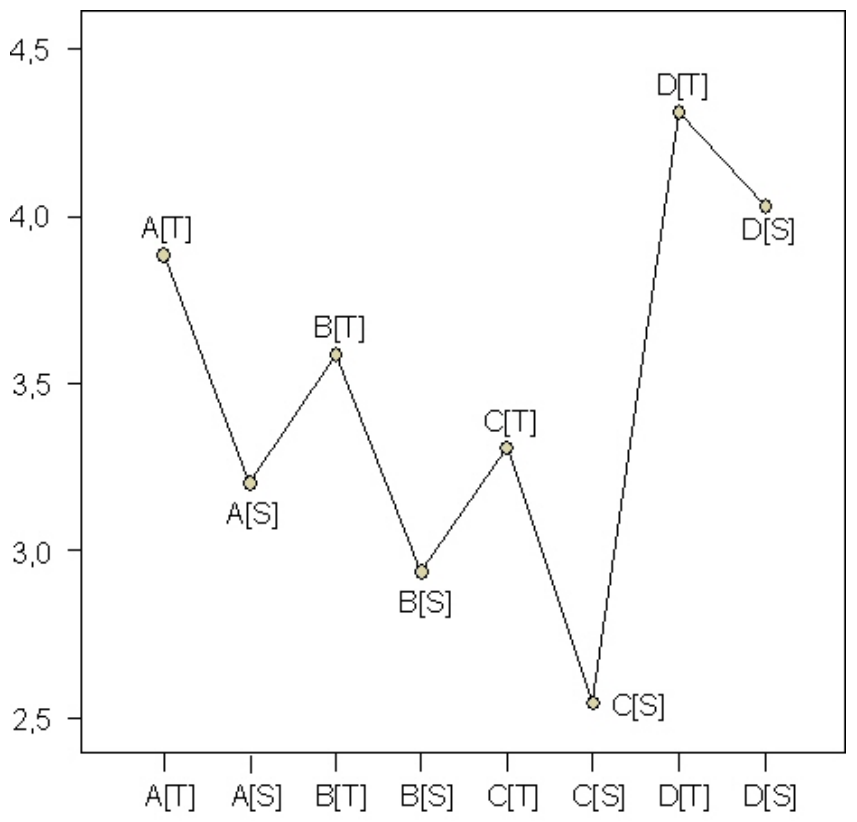

Table 3. Pairwise comparisons

\begin{tabular}{|c|c|c|c|c|c|c|c|}
\hline $\begin{array}{c}\text { (I) } \\
\text { mobile devices }\end{array}$ & $\begin{array}{c}(\mathrm{J}) \\
\text { mobile devices }\end{array}$ & $\begin{array}{c}(\mathrm{I}-\mathrm{J}) \\
\text { Mean difference }\end{array}$ & Sig. & $\begin{array}{c}\text { (I) } \\
\text { mobile devices }\end{array}$ & $\begin{array}{c}(\mathrm{J}) \\
\text { mobile devices }\end{array}$ & $\begin{array}{c}(I-J) \\
\text { Mean difference }\end{array}$ & Sig. \\
\hline \multirow[t]{7}{*}{$\mathrm{A}[\mathrm{T}]$} & $A[S]$ & $.682\left(^{*}\right)$ & .001 & $\mathrm{C}[\mathrm{T}]$ & $A[T]$ & $-.576\left(^{*}\right)$ & .001 \\
\hline & $\mathrm{B}[\mathrm{T}]$ & .296 & .096 & & $A[S]$ & .106 & .633 \\
\hline & $\mathrm{B}[\mathrm{S}]$ & $.946\left(^{*}\right)$ & .002 & & $\mathrm{~B}[\mathrm{~T}]$ & $-.280\left(^{*}\right)$ & .020 \\
\hline & $\mathrm{C}[\mathrm{T}]$ & $.576\left(^{*}\right)$ & .001 & & $\mathrm{~B}[\mathrm{~S}]$ & .370 & .135 \\
\hline & $\mathrm{C}[\mathrm{S}]$ & $1.337\left(^{*}\right)$ & .000 & & $\mathrm{C}[\mathrm{S}]$ & $.761\left(^{*}\right)$ & .003 \\
\hline & $\mathrm{D}[\mathrm{T}]$ & $-.428\left(^{\star}\right)$ & .006 & & $\mathrm{D}[\mathrm{T}]$ & $-1.004\left(^{*}\right)$ & .000 \\
\hline & $\mathrm{D}[\mathrm{S}]$ & -.148 & .521 & & $\mathrm{D}[\mathrm{S}]$ & $-.723\left({ }^{*}\right)$ & .002 \\
\hline \multirow[t]{7}{*}{$A[S]$} & $A[T]$ & $-.682\left(^{*}\right)$ & .001 & $\mathrm{C}[\mathrm{S}]$ & $A[T]$ & $-1.337\left(^{*}\right)$ & .000 \\
\hline & $\mathrm{B}[\mathrm{T}]$ & -.386 & .116 & & $A[S]$ & $-.655\left(^{*}\right)$ & .008 \\
\hline & $\mathrm{B}[\mathrm{S}]$ & .264 & .247 & & $\mathrm{~B}[\mathrm{~T}]$ & $-1.041\left(^{*}\right)$ & .000 \\
\hline & $\mathrm{C}[\mathrm{T}]$ & -.106 & .633 & & $\mathrm{~B}[\mathrm{~S}]$ & $-.391\left(^{*}\right)$ & .002 \\
\hline & $\mathrm{C}[\mathrm{S}]$ & $.655\left(^{*}\right)$ & .008 & & $\mathrm{C}[\mathrm{T}]$ & $-.761\left(^{*}\right)$ & .003 \\
\hline & $\mathrm{D}[\mathrm{T}]$ & $-1.110\left(^{*}\right)$ & .000 & & $\mathrm{D}[\mathrm{T}]$ & $-1.765\left(^{*}\right)$ & .000 \\
\hline & $\mathrm{D}[\mathrm{S}]$ & $-.830\left(^{*}\right)$ & .000 & & $\mathrm{D}[\mathrm{S}]$ & $-1.485\left(^{*}\right)$ & .000 \\
\hline \multirow[t]{4}{*}{$\mathrm{B}[\mathrm{T}]$} & $\mathrm{A}[\mathrm{T}]$ & -.296 & .096 & $\mathrm{D}[\mathrm{T}]$ & $\mathrm{A}[\mathrm{T}]$ & $.428\left(^{*}\right)$ & .006 \\
\hline & $A[S]$ & .386 & .116 & & $A[S]$ & $1.110\left(^{*}\right)$ & .000 \\
\hline & $\mathrm{B}[\mathrm{S}]$ & $.650\left(^{*}\right)$ & .007 & & $\mathrm{~B}[\mathrm{~T}]$ & $.724\left(^{*}\right)$ & .001 \\
\hline & $C[T]$ & $.280\left(^{*}\right)$ & .020 & & $\mathrm{~B}[\mathrm{~S}]$ & $1.374\left(^{*}\right)$ & .000 \\
\hline
\end{tabular}


Using smartphones and tablets in higher education contexts: an exploratory study within a teacher education programme

Parmigiani, Giusto

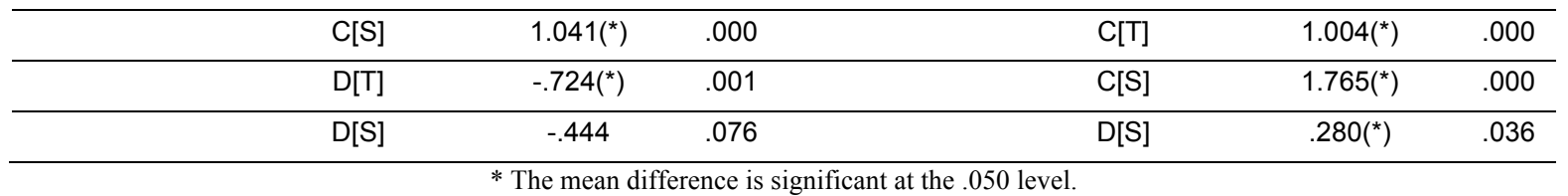

The last quantitative remark emerged from the factor analysis, which was conducted using the main components extraction method and varimax rotation with Kaiser normalisation to detect latent and underlying dimensions. Only pure items and item-factor correlations equal to or greater than.40 in absolute value were considered. As shown in Table 4, three factors emerged for a total explained variance equal to $69.67 \%$.

Table 4. Factor analysis.

\begin{tabular}{|c|c|c|c|}
\hline \multicolumn{4}{|c|}{ Rotated component matrix } \\
\hline \multirow[t]{2}{*}{ Item } & \multicolumn{3}{|c|}{ Component } \\
\hline & 1 & 2 & 3 \\
\hline $\mathrm{A} 1[\mathrm{~S}]$ & .688 & & \\
\hline $\mathrm{B} 1[\mathrm{~S}]$ & .848 & & \\
\hline $\mathrm{B} 2[\mathrm{~S}]$ & .875 & & \\
\hline B4 [S] & .845 & & \\
\hline B5 [S] & .876 & & \\
\hline C1 [S] & .645 & & \\
\hline $\mathrm{C} 2$ [S] & .878 & & \\
\hline C3 [S] & .855 & & \\
\hline C4 [S] & .734 & & \\
\hline $\mathrm{B} 1[\mathrm{~T}]$ & & .877 & \\
\hline $\mathrm{B} 2[\mathrm{~T}]$ & & .627 & \\
\hline $\mathrm{B} 3[\mathrm{~T}]$ & & .806 & \\
\hline $\mathrm{B} 4[\mathrm{~T}]$ & & .865 & \\
\hline $\mathrm{B} 5[\mathrm{~T}]$ & & .823 & \\
\hline $\mathrm{C} 2[\mathrm{~T}]$ & & .912 & \\
\hline C3 [T] & & .775 & \\
\hline $\mathrm{D} 1[\mathrm{~S}]$ & & & .912 \\
\hline $\mathrm{D} 2[\mathrm{~T}]$ & & & .823 \\
\hline D2 [S] & & & .765 \\
\hline
\end{tabular}

The third factor is related to the development of interaction and collaboration among students with both types of mobile devices and confirms the previous observations. The first two factors are interesting because they clearly indicate the difference in the use of smartphones and tablets. Factor 1 can be called Studying and learning with smartphones because it is composed of items included in areas B and C related to this type of mobile device. It explains $38.57 \%$ of the total variance, has an internal consistency (Cronbach's alpha) equal to .935 and consists of nine items with factor loadings ranging from .645 to .878. The second factor can be called Studying and learning with tablets because it is composed of items included in areas B and C related to this type of mobile device. It explains $20.34 \%$ of the total variance, has an internal consistency (Cronbach's alpha) equal to .910 and consists of seven items with factor loadings ranging from .627 to .912 .

\section{Discussion}

When analysing the data grouped in the first sector of Table 2, we find that both types of devices-tablets and smartphones - support interaction and cooperation among students and that they are useful for searching rapidly for information. Thus, we can affirm that the use of both smartphones and tablets can improve interaction and collaboration among students and accelerate the retrieval of information useful for studying. 


\section{Using smartphones and tablets in higher education contexts: an exploratory study within a teacher education programme Parmigiani, Giusto}

The qualitative analysis supports the results in terms of quantitative data. The open-ended question regarding cooperation (area D) was, 'Did the ways of interacting and cooperating among student teachers change when they used mobile devices?' One of the students answered this question by saying, 'Thanks to mobile devices, I've been able to communicate with my university mates from everywhere at any time and to collaborate with them during digital activities very rapidly and in a functional way.'

Combining the quantitative analysis (referring to the second sector of Table 2) and the qualitative data, we can affirm that university activities may be improved with the use of mobile devices. In this case, tablets are more useful because they have large screens and can be used to create digital materials, which seems impossible with smartphones because of their small size. The participants noted that only tablets can support the effectiveness of lectures, workshops and teaching practice to improve the quality of university activities. Smartphones are quick and convenient for the exchange of information and materials, but they are useless for reading, modifying or creating digital materials. One of the participants wrote the following answer to the open-ended question from area A (Can mobile devices improve the organisation of the teacher education programmes?): 'Mobile devices, in particular tablets and iPads, could improve the organisation of university activities because they support active participation, but only if everybody has his own device and a working WiFi connection.' This student noted that the Bring Your Own Device (BYOD) approach has some drawbacks; moreover, a good Internet connection is necessary to conduct a project with mobile devices.

Item B4[T] indicates that tablets do not hinder the use of books or other instruments; on the contrary, they encourage the use of various old (books) and new (personal computers) media, enabling students to study more thoroughly. One of the participants wrote, 'The iPad changed my studying habits. Now I usually have on my desk notes, books and an iPad. It makes the search for information and the reference work on digital materials better.'

Study organisation at home (area B) can be improved mainly by using tablets because the small screens of smartphones do not allow students to easily create digital materials. Tablets appear to be crucial for preliminary study organisation, but some students have difficulty when they have to pick up their digital materials to study for an examination. One of the students said, 'I had prepared many mind maps using Cmaps, but when I opened them to study, I had difficulty reading them on my device. I was more distracted. I had to zoom in and out many times, and the reading was complicated, so studying on my device appeared impossible.' This student emphasised that mobile devices are helpful and effective for collecting data and elaborate materials and information. Therefore, they are suitable for innovative examinations, when students have to present data and materials, or when they have to simulate educational activities. However, mobile devices seem less useful when students have to study for traditional examinations (oral and written tests) because they have to memorize large amounts of information. It is interesting to note the interrelation between digital devices and books in the development of complete and broad studying skills. Many teachers are afraid of using digital instruments because they think that mobile devices will limit the traditional learning opportunities offered by books. However, we found that mobile devices support interaction among old and new technologies.

Area C (learning strategies) is complex because the most critical point is represented by changes in the students' learning styles and strategies. Tablets seem to help students by enhancing the elaboration of relevant information, critical thinking and metacognition, but they do not support the memorisation of information. Consequently, as mentioned, students need to use books to study for the traditional version of the examination. In addition, some students state that mobile devices do not support the improvement of learning styles and strategies: 'I think that the opportunity offered by mobile devices to collect a lot of information contributes to the development of a critical approach, mainly due to the chance to compare the various sources of information. But, from an argumentative point of view, I think that mobile devices do not support a particular improvement.' Another student said, 'The development of critical thinking, in my opinion, does not depend on the instrument but on each individual.' These two statements show that mobile devices are seen as important instruments to gather information and examine materials, but they are not yet seen as crucial for the development of complex and high-level learning competences.

\section{Findings and conclusions}

In conclusion, we can emphasise some of the ways in which mobile devices' affordances may develop and improve the university courses. First, mobile devices can enhance university activities with regard to opportunities to find and share information cooperatively. This is particularly true for tablets, but smartphones are also useful because of their flexibility and because they allow students to contact their classmates to exchange information rapidly.

In general, we can affirm that tablets support changes in educational activities, but it is necessary to provide a tablet for each student because the BYOD system is difficult to apply to the improvement of university courses. The perspective of BYOD is sufficient to start and motivate students in the use of mobile devices, but it is not enough for developing a complete project and for sustaining a deep educational change, which requires good devices.

We want to underline the opportunities offered by tablets in managing a specific aspect of a teacher education programme: the organisation of teaching practice. The students can easily use tablets at school for taking notes and 


\section{Using smartphones and tablets in higher education contexts: an exploratory study within a teacher education programme Parmigiani, Giusto}

pictures, making videos, using apps for teaching and exchanging information with their university mates, as well as during meetings among student teachers and teacher educators at the university. Moreover, tablets support good studying pattern because they help students manage materials and information through the combined use of various media.

Area $\mathrm{C}$ is our main aim for the future: we want to investigate more thoroughly the connection between interaction and the development of critical thinking and learning strategies. It is important to highlight the link between the usefulness of mobile devices in supporting interaction and collaboration on the one hand and a clear and evident improvement in the learning strategies and study organisation of each student on the other hand. For instance, it is necessary to design instructional activities with mobile devices that can allow students to create good-quality digital materials that connect and elaborate the information retrieved online, if possible, in a reflective and collaborative way. Otherwise, mobile devices could be seen only as instruments to retrieve information without opportunities for the development of deep and complex learning. Thus, they could be seen only as tools of a new technology that is not really useful to improve learning in higher education contexts. It is also important to rethink the structure of examinations, which are usually based on either oral or written tests about what students study, rather than about what they are able to do, to foster the skills and competences of students in creating new learning approaches and materials through mobile devices.

\section{References}

Aubusson, P., Schuck, S., \& Burden, K. (2009). Mobile learning for teacher professional learning: Benefits, obstacles, and issues. ALT-J, Research in Learning Technology, 17 (3), 233-247.

Baran, E. (2014). A Review of Research on Mobile Learning in Teacher Education. Educational Technology \& Society, 17 (4), 17-32.

Bates, C. C., \& Martin, A. (2013). Using mobile technology to support literacy coaching practices. Journal of Digital Learning in Teacher Education, 30 (2), 60-66.

Broda, M., Schmidt, A. \& Wereley, M. (2011). Moses was on to something: A reflective analysis of the iPad tablet in field and clinical experiences. In M. Koehler, \& P. Mishra (Eds.), Proceedings of Society for Information Technology \& Teacher Education International Conference 2011 (pp. 3149-3153). Chesapeake, VA: AACE.

Coens, J., Degryse, E., Senecaut, M., Cottyn, J., \& Clarebout, G. (2011). Listening to an educational podcast while walking or jogging: Can students really multitask. International Journal of Mobile and Blended Learning, 3 (3), 23 33.

Ekanayake, S.Y., \& Wishart, J. (2014). Integrating mobile phones into teaching and learning: A case study of teacher training through professional development workshops. British Journal of Educational Technology, 46 (1), $173-189$.

Hargis, J., Cavanaugh, C., Kamali, T., \& Soto, M. (2013). Measuring the difficult to measure: Teaching and learning with an iPad. International Journal of Mobile and Blended Learning, 5 (2), 60-77.

Hashim, Y. (2014). Preliminary study on teachers' use of the iPad in bachelor of education program at a private university in Malaysia. TechTrends, 58 (2), 14-19.

Herro, D., Kiger, D., \& Owens, C. (2013). Mobile technology: Case-based suggestions for classroom integration and teacher educators. Journal of Digital Learning in Teacher Education, 30 (1), 30-40.

Husbye, N. E., \& Elsener, A. A. (2013). To move forward, we must be mobile: Practical uses of mobile technology in literacy education courses. Journal of Digital Learning in Teacher Education, 30 (2), 46-51.

Järvelä, S., Näykki, P., Laru, J., \& Luokkanen, T. (2007). Structuring and regulating collaborative learning in higher education with wireless networks and mobile tools. Educational Technology \& Society, 10 (4), 71-79.

Kearney, M., \& Maher, D.(2013). Mobile learning in maths teacher education: Driving pre-service teachers' professional development. Australian Educational Computing, 27 (3), 76-84.

Kearney, M., Schuck, S., Burden, K., \& Aubusson, P. (2012). Viewing mobile learning from a pedagogical perspective. $\begin{array}{lllll}\text { Research in } 20 . & \text { Rechnology, Learning }\end{array}$ http://researchinlearningtechnology.net/index.php/rlt/article/view/14406

Ling, R. \& Donner, J. (2009) Mobile communications. Polity, London.

Mahruf, C., Shohel, C., \& Power, T. (2010). Introducing mobile technology for enhancing teaching and learning in Bangladesh: Teacher perspectives. Open Learning: The Journal of Open, Distance and e-Learning, 25 (3), $201-215$.

UNESCO (2012). Mobile learning for teachers. Global themes. Retrieved from: http://unesdoc.unesco.org/images/0021/002164/216452E.pdf

Pachler, N., Bachmair, B. \& Cook, J. (2009) Mobile learning: structures, agency, practices. Springer, New York.

Şad, S. N., \& Göktaş, Ö. (2014). Preservice teachers' perceptions about using mobile phones and laptops in education as mobile learning tools. British Journal of Educational Technology, 45 (4), 606-618.

Schuck, S., Aubusson, P., Kearney, M., \& Burden, K. (2013). Mobilizing teacher education: A study of a professional learning community. Teacher Development, 17 (1), 1-18. 
Using smartphones and tablets in higher education contexts: an exploratory study within a teacher education programme

Parmigiani, Giusto

Seppälä, P. P., \& Alamäki, H. H. (2003). Mobile learning in teacher training. Journal of Computer Assisted Learning, $19(3), 330-335$. 